\title{
The Reforms in AI and the Practices of Financial Professionals Training in Higher Vocational Colleges
}

\author{
$\mathrm{Li} \mathrm{Xu}$ \\ Jiangsu Vocational Institute of Commerce \\ Wuxi, China
}

\author{
Qiaoqiao Shen \\ Jiangsu Vocational Institute of Commerce \\ Wuxi, China
}

\begin{abstract}
In the context of expanding the "financial science and technology dividend" and weakening the "demographic dividend", two powers named the efficiency and the cost in conjunction with driving the finance to the development of intellectualization. The development of $\mathrm{AI}$ is going deep into some cores of finance such as risk management and asset pricing. This developed the financial industry to intellectualization. Finance, as an important subject with better appliance, demands the training of financial professionals in colleges and universities as the main of purpose, focusing on the cultivation of comprehensive quality, practical operation ability and the capacity to analyze and solve practical problems. But in the background of AI, in the future, the skills quality and comprehensive of the financial ability, the requirements of skills quality and comprehensive ability will change of the financial industry practitioners, compared to the more practical ability currently, the forthcoming requirement will be higher for the practitioners in the learning ability, multi-disciplinary ability, communication competency, the capability of using AI. Therefore for finance, to set up new teaching philosophy and teaching content have reached a critical state. Meanwhile, along with the development of the Internet and AI, reconstruct teaching method. Though reforming the form of teaching resources, organizational form of teaching, the method of study activity and evaluation method, realize the transformation from knowledge oriented teaching practice to guide the teaching of learning.
\end{abstract}

Keywords-AI ; finance; higher vocational colleges

\section{INTRODUCTION}

In the summer of 1956, Dartmouth College held the first artificial intelligence seminar in history, which was regarded as the symbol of the birth of artificial intelligence. McCarthy first introduced the concept of artificial intelligence, while Newell and Simon presented the logic theory machine. In just a few decades, artificial intelligence has become a highfrequency word in today's society, and closely related to the development of human beings. In 2017, China's artificial intelligence market has reached 216.9 billion yuan, up $52.8 \%$ year - on - year, according to a report from China's Xintong Institute of Artificial Intelligence Industry in 2017. The market size is expected to reach 339 billion yuan by 2018 .According to the 2017 Global artificial Intelligence Talent White Paper released by Tencent Research Institute, there are about 300000 artificial intelligence talents in the world, and by October 2017, China's artificial intelligence talent gap has reached one million levels. For this reason, the Ministry of Education issued and issued the Action Plan for the Innovation of artificial Intelligence in Colleges and Universities. The Action Plan proposes to support colleges and universities in setting up the direction of artificial intelligence in computer science and technology disciplines, and to perfect the discipline system of artificial intelligence. To promote the construction of first-level disciplines in the field of artificial intelligence, to form a new training model of "artificial intelligence $X "$ compound specialty, to build 100 "artificial intelligence $\mathrm{X}$ " compound specialty specialties by 2020 , and to establish 50 artificial intelligence colleges, Research institute or cross research center.

But these numbers and reforms are aimed only at AI professionals. With the development and popularization of AI, the whole human being will live in the era of AI, and everyone will be inseparable from AI. Artificial intelligence serves mankind at the same time, also is competing with human job bowl, bear the brunt possibly is finance industry. As teachers and students majoring in finance in higher vocational colleges, we should be vigilant, take a long-term view, face up to problems, understand problems, solve problems, and let AI become a human being and an assistant rather than an enemy of financial workers.

\section{THE REASONS OF AI GETTING THE RAPID DEVELOPMENT IN THE FINANCIAL INDUSTRY}

As a matter of fact, AI is a branch of computer science, it's essence is to try to let machines or systems simulate the information process of human consciousness and thinking, think like a human being even surpassed humans. AI financial management is the combination of $\mathrm{AI}$ and financial industry. In the book named "Artificial Intelligence", Kai-fu Lee said that finance is the beat foothold of AI, because the date accumulation turnover, storage and update in financial industry, all of these are more than any other industry can meet the big data requirements for the intelligent robot to the learning algorithms deeply.AI need the bottom big data as the support, while the financial industry happened to have the large data. Addition to the demand for asset allocation with the middle classes and HNWIS (High Net Worth Individuals) is becoming more and more vigorous. And because of the development of the technology, the threshold of high quality financial services continues to decline to decline and will cover a large number of ordinary investors 
so, the combination of $\mathrm{AI}$ and finance, must produce a strong "chemical reaction", and AI financial management is possible to "flies into the common family" quickly.

AI meets finance, producing a strong "chemical reaction" in three fields: wind to control, investment adviser and supervision. Financial technology is reflecting the unique value in the innovation of financial transaction a safe and effective transaction and the fuse with technology. The traditional financial Institutions, new technology companies and venture capital investment have become the major force for the development of financial technology.

In the march of 2016, AlphaGo defeated the human being in Weiqi. After this epoch-making "the flare" exploding, a beautiful legend about "intelligent awakening" was well known by the whole world.

\section{A. Social Environment Driven}

The innovation and development of AI in the field of financial technology, is related to the social and economic environment in which the financial assets of the much accumulation in Chinese enterprises and residents, the prevailing of the Internet and the social and economic environment of more and more active the financial transactions. The CEO of CloudBrain, zhang yu said: "The previous waves of outbreaks were driven by the government, were from top to bottom, but this time is proposed by commercially driven, is bottom up". The technology leap, the deep learning and the mature of the neural networks make this intelligent machine molding gradually. Followed by this is the mature of the big data. "In a way, AI is the fruit of big data.AI can grow only on the fertile soil of big data." zhang yu said that AI is a machine, only with "feed" of the big data it can be operable.

\section{B. Government Driven}

It's related to the great situation of china's efforts to push with supply-side structural reform and promote financial marketization of the financial industry. The Chinese government has a keen sense of smell for this time of awakening. In May 2016, the State Council issued the Analysis of "three-year implementation plan of 'Internet + ' artificial intelligence ", put forward the industrial program for AI. During the 2017 national "NPC and CPPCC", the people's Bank of Chinese governor Zhou Xiaochuan pointed out that the Central Bank encouraged the development of financial technology, especially the new technology of the network technology, the digital cash, the Block chain; encouraged technical enterprises to develop the direction of inclusive financial system , changing the phenomenon of financial services in poor and remote areas, the shortage of grass-roots financial services gradually; we should encourage the development and prevent risks as well, to the unhealthy behavior in the progress of development should be regulated continuously. (Zhou Xiaochuan, 2017)

\section{Consumption and Payment Concept Driven}

The number of Chinese consumers is large and the acceptance of Internet financial services is relatively high.
According to the investigation of Boston consulting firm (BCG) ,in Chinese, $80 \%$ of HNWI( high net worth individuals ) accept Internet financial products and services, including tripartite electron to pay, E-banking Internet financial management, robot-advisor, P2P lending network, Crowdfunding and other financial products and services (Wei Bingfei, 2016).

\section{Internet Driven}

The demand for Internet financial services is expanding rapidly. According to the "Blue Book of World CitiesAnnual Report on World Cities(2012) "released by the Shanghai Academy of Social Sciences, expected the number of middle income group in China will reach to $40 \%$ of the total population by 2020 . With the upgrading of consumption ability and consumption structure of middle-income group, China's consumer finance market is bound to grow rapidly, and Internet consumer credit has a great potential for growth. The above two factors determine the strong growth of the market space of the China Fin Tech services. Taking the Red Packet of WeChat as an example, in the Six Day holiday of the Spring Festival of 2016, the total number of WeChat users sending digital red packets is about 32 billion yuan, which is 6 times more than that of PayPal mobile terminals and desktop terminals in 2015. In June 2016, Yu Ebao has the number of customers who served Ant Financial was over 295 million, and the scale of assets managed was equivalent to 96 billion dollars. It has become one of the largest online funds in the world. In a sense, the intelligent wave's coming, is the real "favorable climate and geographical position and support of the people ". So, on many occasions, Robin Li announced in a passionate manner: "the intelligent revolution is coming."

\section{THE INFLUENCE OF ARTIFICIAL INTELLIGENCE ON FINANCIAL PRACTITIONERS}

\section{A. The Influence of Artificial Intelligence on Banking Practitioners}

According to the China Banking Regulatory Commission, issued by the CBRC 2015 report, as of the end of 2015, China's banking and financial institutions have a total of 4,262 legal institutions, 3.8 million practitioners. And compared to the specific number of banks, most banks in three consecutive years of downsizing, as of the end of 2016, ICBC was a total reduction of 14090, the Agricultural Bank of 10843 people, the construction bank to reduce 30007 people, and this trend is becoming normalized. Correspondingly, the rate of bank departure is rising rapidly, and the departure rate is usually regarded as the ratio of the bank's Internet service to the offline counter. According to the Banking association, the amount of offshore banking transactions in 2016 amounted to $\$ 1522.54$ trillion, with the industry averaging $84.31 \%$ off the counter. Under the environment of the overall transformation of the domestic banking industry, the introduction of intelligent system can greatly reduce the labor cost from the angle of enterprise profit. According to a study of 8 banks using artificial intelligence to improve cash-stock operations, the report 
found that the front office, which uses the most digital processing, doubled the income of eight times per employee and doubled the number of tasks handled by each employee in the background department by four times. The report predicts that the quality control and compliance business in the middle and middle sector, as well as the capital market business that receives potential customer information from the front desk to generate transaction contracts, can reduce at least one-fourth of the workforce. The background department of it, finance and personnel business for the processing of documents and data, no longer need manual labor input and scanning, may lead to the abolition of onethird of the post. In fact, the use of machine learning, natural language processing, cognitive technology, automated processes, intelligent workflow Tools has become the global investment industry trends.

\section{B. Impact of Artificial Intelligence on Insurance Practitioners}

In January 2017, Fukoku Mutual life Insurance, the Japanese life giant, plans to cut nearly $30 \%$ of its insurance claims assessment staff and will introduce IBM's Watson AI system to improve operational efficiency. Ant Gold Clothing under the insurance platform has also recently released a "fixed damage treasure" products, through the depth of learning and image recognition detection, fixed loss can replace the traditional car insurance fixed loss, in a matter of seconds can give accurate claims results. Interestingly, though, the machine is still a man of ulterior motives. An insurance veteran has introduced that his group has adopted machine-defined damage, but found it difficult to identify cases of deliberate deception, or whether people need to operate. In the development of insurance premiums, UBI (usage-based Insurance) technology has been introduced to provide product pricing for insurance companies through data collection and analysis. Insurance pricing is one of the core works of actuaries and requires considerable subjective decision-making power, but this work is being replaced by artificial intelligence.

\section{Impact of Artificial Intelligence on Investment Practitioners}

In today's world, the best development of AI is undoubtedly the United States and Japan. In the field of AI financing, the United States and other developed countries have also come ahead. WFC, BAML, Fidelity International, Goldman Sachs, pioneer, Schwab, BlackRock and other traditional giants have entered the smart investment business. As of February 2017, pioneer funds used "Machine + artificial" private consultancy services to manage assets of about US \$47 billion, the world's largest independent intelligent platform betterment management scale of $\$ 8$ billion. The first "special analysis of Artificial intelligence financing Market", published by Analysts July 25, shows that the application of artificial intelligence finance has been raised to a new level in the global context. By 2020, China's artificial intelligence management is expected to reach 5.22 trillion yuan.

\section{COPING METHODS OF FINANCIAL PRACTITIONERS IN THE CONTEXT OF ARTIFICIAL INTELLIGENCE}

Mao Zedong said, the enemy, battles. With the advent of artificial intelligence, only analysis of the advantages and disadvantages of artificial intelligence, with an open mind, embrace the future, and prepare for the future, in order to be invincible.

\section{A. Advantages of Artificial Intelligence}

There has been a lot of concern about artificial intelligence: Hawking says artificial intelligence can lead to human extinction, and Bill Gates argues that human beings need to fear the rise of artificial intelligence, and that Musk is the greatest threat to human survival. There are also many problems in the development of AI financing.

AI developers are technology companies, technology companies have a listed company's dynamic trading data, the more the development of science and technology, the higher the degree of interconnection, AI master real-time Business data more accurate, this advantage decided to give the money to artificial intelligence everyone can get a higher rate of return. For example, with the support of the cat and Ali pay data, future Ali AI will get the company's performance report sooner than the Treasury of the listed company, and take action before the United States releases its quarterly bulletin. The point is that the data collected by the cat and Ali pay, though not all, but still large data, the changes in the data and the overall performance of the United States is basically synchronized, for the United States financial personnel, the data to be summed up the results, but for artificial intelligence is every moment has a result. This is tantamount to bully the blind.

AI is enough objective. Money to AI is the number, not affected by short-term fluctuations, not affected by emotions. And it is easy to spot the potential stocks of performanceindex growth.

AI has super memory (daily trend map) ability, that is, TA can be in a few seconds according to the history of the formation of large data to advance the trend of the stock (know how to play the dealer), so can become a super shortterm master.

The first 3 overwhelming advantage decided that the public will give the funds to AI care, will form 100,000 yuan $\mathrm{x} 1$ million people choice effect. This effect allows the AI to fully control the disk surface, the reasonable allocation of funds to the excellent enterprise, so that innovation accelerated, so that all shareholders to achieve a stable high yield.

\section{B. Disadvantages of Artificial Intelligence}

Wall Street News has previously mentioned that although robotic voting has attracted a large number of individual investors. However, compared with personal financial advisers, there are many limitations in the network platform's robot investment. 
Face-to-face personal financial advisers not only cover the field of investment, but also help clients manage cash flow, make pension plans, buy business insurance, help with college tuition loans and real estate loans. Also, as a complete investment plan should take account of all the financial needs of customers, rather than simply a simple venture capital preference survey based on the adjustment of asset allocation.

A single account cannot be very good tax avoidance planning. Many investment assets need to be family-related and the investment involved in taxation needs to be taken into account, such as placing tax-exempt assets in a taxpaying account, placing an exempt asset in an individual Retirement Account (IRA), deferring the tax on the IRA account to the present, and thereby relieving some of the tax. For the above-mentioned tax measures, it is difficult for robots to be properly arranged.

In the use of artificial and computer intelligence, simple innovation cannot meet the complex needs of customers, the development of relevant needs of the fund companies are also facing the challenges of the various functions to make trade-offs.

The robot to invest to some extent can replace the analyst's quantitative analysis, but it is difficult to replace its qualitative analysis.

Network and property security: The application of AI in the financial field has caused many people to be worried. Outlaws may use AI to gain privacy and financial data. But the ant Gold Clothing vice president, the chief data scientist lacquer far thinks, the technology is neutral, but human has the choice. AI can be used for fraud, but it can also be used to analyze the systemic risk or credit in today's socioeconomic system, thus promoting the development of a good financial society.

The danger of subverting the industry: AI Future is the financial industry assistant, or the industry's subversive? The large-scale application of AI will certainly replace many of the human work, will it lead to social instability?

Now we are in the "weak AI era". Due to the immaturity of technology and applications, the weak AI era gives investors the impression that "losses are more than the time to make money". Many investors said that the effect of the application of some of the smart investment system is not ideal, income is not high or even loss.

\section{The Future of Artificial Intelligence}

The development of artificial intelligence should not and will not be the replacement of financial practitioners, but the liberation of all the heavy, repetitive, statistical and computational work entrusted to artificial intelligence, leaving behind is thought.

The artificial intelligence financing is the time and the industry development tendency, the trend is irreversible, also unstoppable. According to "New generation of Artificial Intelligence development Plan", by 2020, the artificial intelligence core industry scale surpasses 150 billion yuan, drive the related industry scale over trillion. "This market has huge demand, the development prospect is limitless." What we need to do is embrace artificial intelligence, use AI, use the time lag to develop the ability that artificial intelligence does not have, use artificial intelligence ability, thus more effective work.

\section{The Transformation OF CONTENTS OF Training PROFESSIONAL TECHNICAL TALENT IN FinANCE UNDER THE BACKGROUND OF AI}

\section{A. The Requirements of the Financial Industry for the Talent Quality}

Financial industry is the core of modern economy. Financial industry is a special service industry, which has great social impact and objectively requires financial consultant to have good professional ethics. AI don't have moral tendencies, and the moral level of the users of AI and the operators determine the order of the financial industry. As a financial consultant, love of the motherland, love people, loves our work, with due diligence, fairness, have the ability to distinguish right from wrong, and the ability to distinguish the authenticity.

\section{B. Professional Skills Do the Need of Financial Talents}

1) Lifelong learning: Although China is still lagging behind some developed countries, she is developing at an amazing speed. At the same time, the innovation of science and technology is a catalyst, the strong chemical reaction is making China have far-reaching changes, all works of life need to constantly update their knowledge reserve and their knowledge structures .Only lifelong learning can catch up with the China's rate of development ,only lifelong learning will be able to keep up with the times development, only lifelong learning can get a toehold, only lifelong learning can enjoy the economic development to the people's conveniences and welfares.Therefore, during the period of University, we need to train from the concept of lifelong learning, the craft of lifelong learning, the avenues to obtain knowledge, the formation of habits, the ability of autonomous learning etc. , and form specialized courses and atmosphere.

2) "Multidimensional" lore framework: The finance demand of talents in the future is also diversified. This is exactly what AI does not have. The so-called "multidimensional" is to understand more and wider. Not only related to banking, finance, insurance, futures and other financial knowledge concerned, but also political, economic, legal, Internet etc. .It also needs an international perspective to adapt to the globalization and the information era be linked up to international standards.

According to the Xinhua News Agency, Beijing, April 26th, the Political Bureau of the Central Committee of the Communist Party of China carried out fortieth collective learning on the maintenance of national financial security in the afternoon of April 25th. Xi Jinping, general secretary of the CPC Central Committee, emphasized that financial 
safety is an important part of national security and is a mainstay of our economy running smoothly. Maintaining financial security is a strategic and fundamental event which is related to the overall economic and social development of our country. Financial work, economic life, financial be stability, economic will be stability. We must fully find out the importance and role of Finance in economic development and social life. We should maintain financial security as a major task in governing the country and do a solid job in financial work.

Finance, economy, politics and military form an indivisible whole. Only the human mind can establish a unified concept from macro to micro, find the countless ties between these aspects. Aimed at the emergency about political, economic or military, judge it's impact to finance. Similarly, we can find the impacts to international politics, economics and military through the trend of financial incidents. Besides from the knowledge of history, humanities, geography, aesthetics and art will also have a certain impact on finance.

3) The fields have been distinguished detailed, complicated and microcosmic: Due to the increasingly internationalization of financial and economic activities, the trend of security, complexity and microcosmic of banking institutions and financial activities, the business contents are different because of the difference of demand sides. Therefore, the requirements for talents have their own characteristics, and the required financial knowledge to the talents is wider and higher. With the use of AI, simple repetitive operation must be further decrease and simplify .For those talents who can do business operations complicated, product development and market development, which is good at marketing, is proficient in financial analysis and can do effective risk reduction. These talents need to have the knowledge of accountancy and jurisprudence in addition to the basic knowledge of finance such as the management of the risky portfolio, the stock fundamental analysis and the methods of technical analysis. Financial companies need the talents who thoroughly understand the economic and financial situation, with modern financial marketing consciousness, can lay down the financing strategy and target Equality Financing based on the micro enterprise financial situation and the macro economic situation. Which is simply means that talents who know how to use AI are needed.

\section{The Basic Quality Demand of the Talents in the Financial Industry}

1) Interpersonal ability and coordination capacity: Financial professionals need rich experience in financial employment, with excellent professional ethics, favorable communication ability and strong adaptability. No matter how better the professional, if he lacks ability to relate, he can't distinctly express the information that he wants to express, and can't communicate with, colleagues or subordinates clearly or simply, even can't effectively convey information and cannot effectively work. If he lacks adaptability, and can't quickly integrate into the new collective and new environment, and always want to highlight individuality, he will be against the fixed culture of financial enterprises, and it is hard to get the recognition from work.

EQ is not possessed by a robot. In any industry, is the human who controls the robot and be served by robot. The ultimate society is going to deal with the relationship between people. AI is the only tool to communicate and handle the relationship. "Love "is the basic of human life. The "temperature "is the most important part of interpersonal skills. All industries need to be based on "love", care for vulnerable groups, and combine with fairness, make policy by "temperature", and provide humanized service.

2) Creatively, planning ability and the thinking ability of "cross-cutting": AI does not have creativity, planning ability, and "cross-cutting" thinking ability. Therefore, established on crossover, rooted in creation, based on "love", considering the factors of history, humanity, geography and art. Nowadays at the foundation of policy, economics and military both in parliament and outside, provide innovative work in services is the main work trend in the future.

VI. The Transformation OF METHOdS OF Training PROFESSIONAL TECHNICAL TALENT IN FINANCE UNDER THE BACKGROUND OF AI

\section{A. Offer Classes for Concept Education}

EQ and IQ are always described as two fundamental qualities for human being, but few specific courses have been added to the curriculum. Traditional Chinese culture believes in the osmosis, teaching standards of conduct through historical stories and educating its people in skills of communicating and dealing with each other by a big family, but currently many students lack the access as a result of the gradually diminishing family units caused by fast pace of modern society. Therefore, schools are supposed to modify their curriculum, letting students know what sociability, negotiation and sophistication are and how happy they will feel when they learn sympathy better and the ways of caring. Unlike machines, human are warm-blooded, and only the people with qualified EQ can perfectly master the AI.

\section{B. Construction About Diverse Curriculum, Elective System of Cross-disciplinary and Cross-major}

Talents we need are diverse and cross-major. Apart from learning professional knowledge about their major, its necessary for students to learn other professional knowledge which they are interested in, however, different people have different ability, interest and energy, only unlimited elective system can meet diverse needs of people at extreme, as the saying goes "Every has field has it's master "Human being can't compare with $\mathrm{Al}$ in the aspect of calculating and solving big date, but I can make ourselves a comprehensive learner and improve our uniqueness through learning other fields Knowledge constantly, irreplaceability is a very large 
challenge for school curriculum system, it's worthwhile to probe and try, through it can't success at once.

\section{Creation Make as Unique. Innovation Is the Origination of Competitiveness}

Our originality will never be replaced by robots, human being will be the worker with creation, innovation, originality. Our college can cultivate our students crossfield learning ability. Thought these items thinking logic, judging ability under hazy situation, students can make exact judge and become and messy model judge, school can cultivate students these ability thought scene simulation and creation, startup, aesthetics curriculums.

\section{Ability Cultivation of HMI Interactive}

AI will be an essential part of human life, like the computer, the Internet, and smart phones. Because computers, Internet and computers are spreading fast, most people only have a preliminary understanding and use of computers and smart phones. Their efficiency is not high. The efficient use of AI is one of the necessary abilities of the outstanding talents in the future.

\section{E. Interaction Online and Offline, Bring Before and After Class Together and Understand Thoroughly}

The transformation of contemporary knowledge, the change of learning styles, the transition of teaching media and the emerge of OCW (Open Course), have called for the renewal of education wisdoms and the transformation of teaching methods. The key to the reform of teaching methods is to change the concept of education. Stick to the principle opening-up. Increase the percentage of learning, integrate into the information elements, and realize the deep interaction. Students use AI to complete basic ingredients learning, and abandon repetitive, inefficient and low quality courses and abilities. Focus the core course on guidance, discussion, topic establishment and design. This will ask for higher requirements for teachers' ability.

\section{F. EQ Course}

All the way through, EQ and IQ are considered to be two important aspects of human being, but it's hardly have courses to focus on these two aspects. Old Chinese culture advocated imperceptibly, put all philosophies into historical stories. In real life, the methods of dealing with people trend to be eradicated by big families. However, when the society enters the fast track, the family unit becomes smaller and many students lack the channel of learning the skills of dealing with people. The school should let students understand the social ability, negotiation skills, social understanding, experience sympathy, concern for others. People are boiling with humanity. Only those with EQ can control AI better.

\section{CONCLUSION}

No-driver bus in Shenzhen has come in to use in December 2, 2017. It represented a milestone of a tendency that drivers would withdraw from this time. According to
Mckinsey Analisis report, there will be 800 million careers disappearing all over the world. It's a pleasant thing that AI comes, we'll finally say goodbye to those jobs which are heavy, repeated, calculative, which even threaten our health and then lead to a happy life. However, there're much more brand-new jobs would be created as well. So it comes and provides us a new subject: dominating AI. Chances always prefer those prepared mind. Let's start it now and make the educational system prior to facts.

\section{REFERENCES}

[1] Tian Guangw ei, Analysis of Financial Practice Teaching Mode in Colleges and Universities Facing the Cultivation of Applied Talents, Heilongjiang Higher Education Research, 2016(1)

[2] Hua Chi 1, "Experimental Training Teaching System Design in the Background of "Internet Plus", Experimental Technology and Management, 2016(3)

[3] PBC Wuhan Branch Office Task Force, Application and Response of Artificial Intelligence in the Financial Sector, Wuhan Finance, 2016

[4] Research Group of the People's Bank of China, Guangzhou Branch Comparison and Enlightenment of China-US Financial and Technological Development, Southern Finance • Total 489, 2017, (5)

[5] Li Yanyu, Wu Qiang. The response of commercial banks under the wave of financial technology [J]. Tsinghua Financial Review, 2016, (10).

[6] $\mathrm{Li}$ Wei. Electronic banking in the era of financial technology $[\mathrm{J}]$ China Finance, 2017, (1)

[7] Zhong Zenghong, Song Ying, Mao Ruifeng. The impact of financial technology [J]. China Finance, 2017, (4).

[8] Wang Guangyu, He Junni. The future and responsibility of financial technology [J]. Southern Finance, 2017, (3).

[9] Ba Shusong, Bai Haifeng. The development process of financial science and technology and the exploration of core technology application scenarios [J]. Tsinghua Finance Review, 2016, (11).

[10] Wei Bingfei. Comparison and consideration of China-US financial technology [J]. Tsinghua Financial Review, 2016, (10).

[11] Ba Shu Song. The status quo and trend of China's financial science and technology development $[\mathrm{N}]$. 21st Century Business Herald. 2017-01-20(004)

[12] Tian Guangwei, Teaching Mode in Colleges and Universities Facing the Cultivation of Applied Talents: Analysis of Financial Practice, Heilongjiang Higher Education Research, 2016(1)

[13] Hua Chi 1, Experimental Training Teaching System Design in the Background of "Internet Plus", Experimental Technology and Management, 2016(3)

[14] PBC Wuhan Branch Office Task Force, Application and Response of Artificial Intelligence in the Financial Sector, Wuhan Finance, 2016

[15] Research Group of the People's Bank of China, Guangzhou Branch, Comparison and Enlightenment of China-US Financial and Technological Development, Southern Finance • Total 489, 2017, (5)

[16] Li Yanyu, Wu Qiang. The response of commercial banks under the wave of financial technology [J]. Tsinghua Financial Review, 2016, (10).

[17] $\mathrm{Li}$ Wei. Electronic banking in the era of financial technology [J] China Finance, 2017, (1)

[18] Zhong Zenghong, Song Ying, Mao Ruifeng. The Effects of financial technology [J]. China Finance, 2017, (4).

[19] Wang Guangyu, He Junni. The responsibilities and future of financial technology [J]. Southern Finance, 2017, (3).

[20] Ba Shusong, Bai Haifeng. The development process of financial science and technology and the exploration of core technology application scenarios [J]. Tsinghua Finance Review, 2016, (11). 
[21] Wei Bingfei. Comparison and consideration of China-US financial technology [J]. Tsinghua Financial Review, 2016, (10).

[22] Ba Shu Song. The status and trends of China's financial science and technology developments [N]. 21st Century Business Herald. 201701-20(004)

[23] Sun Fangjiao ,The Reform of Financial Education and Talents Development against the Backdrop of the Integration of Technology and Finance, [J],Shanghai Finance, 2013(8) 